\title{
Ra'anan S. Boustan, From Martyr to Mystic, Rabbinic Martyrology and the Making of Merkavah Mysticism
} Tübingen, Mohr Siebeck, coll. " Texts and Studies in Ancient Judaism » 112, 2005, XXII+376 p.

Jean-Daniel Dubois

\section{(2) OpenEdition}

Journals

Édition électronique

URL : http://journals.openedition.org/assr/9943

DOI : $10.4000 /$ assr.9943

ISSN : $1777-5825$

Éditeur

Éditions de l'EHESS

Édition imprimée

Date de publication : 1 décembre 2007

Pagination : 157-310

ISBN : 978-2-7132-2145-3

ISSN : 0335-5985

Référence électronique

Jean-Daniel Dubois, «Ra'anan S. Boustan, From Martyr to Mystic, Rabbinic Martyrology and the Making of Merkavah Mysticism », Archives de sciences sociales des religions [En ligne], 140 | octobre - décembre 2007, document 140-10, mis en ligne le 29 janvier 2008, consulté le 21 septembre 2020. URL : http:// journals.openedition.org/assr/9943; DOI : https://doi.org/10.4000/assr.9943

Ce document a été généré automatiquement le 21 septembre 2020.

(c) Archives de sciences sociales des religions 


\section{Ra'anan S. Boustan, From Martyr to Mystic, Rabbinic Martyrology and the Making of Merkavah Mysticism}

Tübingen, Mohr Siebeck, coll. " Texts and Studies in Ancient Judaism » 112, 2005, XXII+376 p.

Jean-Daniel Dubois

1 Cette étude de martyrologie rabbinique s'inscrit dans le courant du renouveau des études sur les textes mystiques juifs, et particulièrement ceux de la mystique du Char (Merkavah), célèbres pour leurs techniques «d'ascension» devant le Trône divin. En choisissant l'Histoire des Dix Martyrs, l'auteur rend compte d'une partie de la littérature dite des Palais (célestes), les Heikhalot Rabbati. Contrairement aux études initiées par G. Scholem qui avaient tendance à dater très haut ce genre de corpus, au temps de la formation de la littérature tannaïte et talmudique, proche des révoltes juives contre l'empire romain, l'auteur prend le parti de suivre son mentor, Peter Schäfer, à qui l'on doit de nombreuses éditions, traductions et études de ce genre de textes; R.S. Boustan propose ainsi une analyse historique et littéraire qui situe l'essentiel du corpus des Heikhalot Rabbati au Moyen Âge, en tout cas après la fin de l'Antiquité tardive. L'introduction et le premier chapitre de ce livre sont consacrés aux questions de méthode et d'approche de ce type de littérature. En rappelant les grands traits de l'histoire de la réception et de la transmission de ce corpus de textes mystiques (avec la liste des manuscrits concernés et un bref état de leur contenu selon les diverses compilations, pp. 38-46), R.S. Boustan souligne que l'Histoire des Dix Martyrs fait partie de ces textes plus anciens qui ont pu circuler avant d'être intégrés aux Heikhalot Rabbati. Les traditions martyrologiques de l'Histoire des Dix Martyrs ont été renarrativisées par leur insertion dans les Heikhalot Rabbati.

2 Pour comprendre le propos martyrologique de l'Histoire des Dix Martyrs, R.S. Boustan compare certains traits de cette histoire au reste des traditions talmudiques sur les martyrs, afin de situer son étude à la période byzantine, principalement entre les $\mathrm{v}^{\mathrm{e}} \mathrm{et}$ $\mathrm{VII}^{\mathrm{e}}$ siècles. L'auteur perçoit une préoccupation caractéristique des récits 
martyrologiques qui lient la souffrance du martyr à l'existence de ses péchés. Mais la mise en valeur, dans cette Histoire, de deux martyrs exemplaires, Rabbi Ishmaël ben Elisha et Rabbi Simeon ben Gamaliel, montre que l'on passe progressivement à un discours qui met en scène l'opposition entre le Patriarche, chef suprême de la religion juive, et le Grand-Prêtre. L'histoire biblique du patriarche Joseph vendu par ses frères sert à illustrer la souffrance collective d'un peuple payant pour son erreur avec la mort des Dix Martyrs, souffrance rappelée aussi dans la liturgie du Jour du Grand Pardon. Plusieurs chapitres de cette étude envisagent des thèmes caractéristiques de l'Histoire des Dix Martyrs afin de montrer comment cette série de traditions martyrologiques diverge par rapport au reste des Heikhalot Rabbati, et comment l'on peut comprendre, du coup, la spécificité de cette Histoire. Par exemple, l'histoire miraculeuse de la conception céleste de Rabbi Ishmaël ben Elisha, grâce à la rencontre de sa mère avec le personnage de Metatron, explique ses capacités à pratiquer la mystique du Char. Les traditions sur son "ascension", son exécution et le rite de son masque mortuaire rapprochent Rabbi Ishmaël des figures messianiques célestes de Métatron et Melchisedek. On y perçoit de temps en temps des allusions aux conceptions chrétiennes contemporaines sur la figure sacerdotale du Christ ou sur la naissance miraculeuse de Jésus ou de Marie. En tout cas, le statut particulier de Rabbi Ishmaël, de condition divine et humaine par sa beauté angélique et sa pureté, justifie son aptitude à pratiquer les exercices et les techniques magiques d'ascension céleste et de «descente » du Trône.

3 Le culte des martyrs met en place ici un discours sur la souffrance vicaire des Dix Martyrs, expiant les fautes du peuple d'Israël, depuis la vente de Joseph par ses frères. Et les traditions martyrologiques sur le trône divin qui remplace le Temple de Jérusalem détruit, sur le sang des martyrs ou sur l'annonce de la vengeance divine contre Rome, marquent leur ancrage dans des traditions apocalyptiques. L'Histoire des Dix Martyrs sait puiser aux sources apocalyptiques, liturgiques et midrachiques très anciennes pour innover.

4 On appréciera tout au long de ces chapitres comment l'auteur compare textes en main (cf. les deux annexes, sur l'évolution des textes martyrologiques, et sur les diverses présentations de la scène du jugement céleste) plusieurs formes d'une même tradition afin de souligner que l'Histoire des Dix Martyrs constitue un ensemble littéraire cohérent. Circulant avec beaucoup d'agilité dans la masse des traditions midrachiques médiévales, l'auteur sait profiter d'une abondante bibliographie pour présenter un contexte historique et littéraire vraisemblable pour cette tradition des Dix Martyrs. Une comparaison raisonnée de l'histoire des martyrs avec le reste des Heikhalot Rabbati fait apparaître, surtout dans le dernier chapitre, que les traditions de la confrérie des rabbins qui cherchent à pratiquer la mystique du Char attestent d'un conflit avec les partisans d'un judaïsme rabbinique tenant aux revendications des descendants d'une lignée sacerdotale. Le conflit entre Rabbi Ishmaël accompagné de ses partisans mystiques visionnaires et le Patriarche serait l'indice de l'ancrage des traditions martyrologiques étudiées dans la Babylonie byzantine au début de l'époque gaonique. Malgré sa spécialisation, cette étude ne manquera pas de piquer la curiosité des familiers de la littérature mystique juive; elle intéressera tout aussi bien les historiens des martyrs du christianisme ou de l'islam, en particulier quand les traditions martyrologiques sont utilisées pour justifier des pratiques de spiritualité hors du commun. 